\title{
CONSIDERACIONES ACERCA DEL CONCEPTO KANTIANO DE OBJETO TRASCENDENTAL
}

\author{
Ileana P. Beade* \\ Universidad Nacional de Rosario, Argentina \\ ileanabeade@yahoo.com.ar
}

\begin{abstract}
The concept of Transcendental Object either refers, in the framework of the Critic of Pure Reason, to the cause or foundation of external phenomena, or, on the contrary, to the concept of an object in general as it is thought by the conscience so as to guarantee the objective validity of its representations. In this paper, I shall attempt to show that - contrary to what has been suggested by several interpreters - the ambiguity involved in the Kantian use of this concept is not the result of a terminological carelessness, but that it is founded on certain principles of Critical Idealism.

Key Words: Transcendental Object, Thing in itself, Noumenon,Phenomenon.
\end{abstract}

\begin{abstract}
Resumen
El concepto de objeto trascendental hace referencia, en el marco de la Crítica de la razón pura, a la causa o fundamento de los fenómenos externos, o bien, por el contrario, a un concepto de objeto en general pensado por la conciencia a fin de garantizar la validez objetiva de sus representaciones. En este trabajo se intentará mostrar que — contrariamente a lo sugerido por diversos intérpretesla ambigüedad implicada en el uso kantiano de este concepto no es resultado de un descuido terminológico, sino que se funda en principios doctrinales del idealismo crítico.

Palabras Clave: objeto trascendental, cosa en sí, noúmeno, fenómeno.
\end{abstract}

*Recibido: 15-03-09. Aceptado: 13-05-09.

* Profesora de la Cátedra de Historia de la Filosofía Moderna de la Facultad de Humanidades y Artes de la Universidad Nacional de Rosario (República Argentina). Becaria Post-doctoral del Consejo Nacional de Investigaciones Científicas y Técnicas (CONICET). 
El concepto de objeto trascendental (OT) es utilizado en la Crítica de la razón pura $(\mathrm{KrV})$ según dos acepciones diversas: en ciertos pasajes, Kant se refiere al OT en tanto causa o fundamento de los fenómenos externos; en otros pasajes, el término alude, en cambio, a un concepto de objeto en general (concepto que - como veremos- tiene la función de garantizar la validez objetiva de nuestras representaciones). A continuación intentaremos mostrar que - contrariamente a lo sugerido por diversos intérpretes ${ }^{1}$ — la ambigüedad implicada en el uso kantiano de este concepto no es resultado de un descuido en el uso de los términos específicos (descuido atribuido a Kant con suma frecuencia), sino que dicha ambigüedad se funda en principios doctrinales del idealismo crítico. Atendiendo a este objetivo, examinaremos, en primer lugar, (1) aquellos pasajes en los que el OT es concebido como causa o fundamento de los fenómenos externos; en segundo lugar, (2) analizaremos aquellos textos en los que el término es empleado según la segunda acepción mencionada, y consideraremos los motivos que permiten explicar su uso ambiguo en diversos pasajes de las obras críticas; finalmente, (3) haremos una breve referencia a la relación que la noción de OT guarda con los conceptos de cosa en sí y de noúmeno, con los que resulta usualmente identificada.

\footnotetext{
${ }^{1}$ Cf. Sergio RÁbade Romeo: Kant. Problemas gnoseológicos de la Crítica de la Razón pura, Madrid: Gredos 1969, p. 108; Norman Kemp SMITH: A commentary to Kant's Critique of Pure Reason, New York: Humanities Press 1962, p. 412; Erich ADICKES: Kant und das Ding an Sich, Berlin: Panverlag Rolf Heise 1924, p. 100. A propósito de las críticas formuladas por los intérpretes con respecto al uso ambiguo de conceptos específicos en la $\mathrm{KrV}$, coincidimos con Allison, quien señala: "It is no doubt easy to read the Critique of pure reason in such manner, immediately dismissing all difficulties and apparent contradictions as [...] cases of careless terminology, especially since the Critique abounds with such carelessness. It does, however, seem worth the effort to see if this undeniable ambiguity can be explained on other, more philosophical grounds" (Henry Altison: "Kant's Concept of the Transcendental Object", Kant-Studien 59 [1968], p. 166).
} 


\section{El objeto trascendental como causa o fundamento del fenómeno}

En diversos pasajes de la $K r V$, Kant recurre a la noción de OT para referirse a la causa o fundamento desconocido de los fenómenos externos:

Los fenómenos externos se atribuyen a un objeto transcendental que es la causa de esa especie de representaciones, [objeto] que, empero, no conocemos, y del que jamás llegaremos a tener concepto alguno (A 393) ${ }^{2}$.

El objeto transcendental que sirve de fundamento de los fenómenos externos $[\ldots]$ no es $[\ldots]$ sino un fundamento, desconocido para nosotros, de los fenómenos (A 379380).

Aquel algo que sirve de fundamento de los fenómenos externos, y que afecta a nuestro sentido de tal manera que éste recibe las representaciones de espacio, de materia, de figura, etc., este algo, considerado como noumenon (o mejor, como objeto trascendental) $[\ldots]$ no es extenso, ni impenetrable, ni compuesto, porque todos esos predicados conciernen solamente a la sensibilidad y a la intuición de ella, en la medida en que somos afectados por tales objetos (por lo demás, desconocidos para nosotros) (A 358).

El fenómeno externo es considerado en el marco de la doctrina crítica como una representación de la conciencia ${ }^{3}$. Más allá de las dificultades

${ }^{2}$ La paginación citada corresponde a la Edición Académica de las obras kantianas: Kants gesammelte Schriften, Berlin: herasugegeben von der Königlich Preussischen Akademie der Wissenschaften 1903/1911, I-IX. A esta edición aludimos, de aquí en adelante, bajo la abreviatura Ak., seguida del número de tomo, indicado en números romanos. En el caso de las citas correspondientes a la Crítica de la razón pura [Kritik der reinen Vernunft], nos referimos a la primera y a la segunda edición bajo las abreviaturas A y B, según el uso convencional. Citamos la traducción española: Immanuel KANT: Crítica de la razón pura, traducción de M. Caimi, Buenos Aires: Colihue 2007.

3 "El concepto trascendental de los fenómenos en el espacio es una advertencia crítica de que en general nada de lo intuido en el espacio es una cosa en sí; y de que 
que plantea la concepción crítica del objeto dado en la experiencia como entidad puramente representacional (dificultades cuyo análisis excede el objetivo que nos hemos propuesto para el desarrollo de este trabajo), interesa destacar que el fenómeno, en tanto representación, se constituye — según establece Kant— a partir de la afección que algo externo ejerce sobre la sensibilidad (algo que admite ser considerado entonces como su causa o fundamento). En uno de los pasajes anteriormente citados, Kant afirma que aquello que nos afecta dando origen a nuestras representaciones empíricas —a saber: el $\mathrm{OT}^{4}$ — no es extenso, ni impenetrable, ni compuesto, pues estos predicados — sostiene- corresponden únicamente al objeto en tanto es intuido por la sensibilidad (i. e., corresponden al objeto como fenómeno). Aquello que afecta nuestra capacidad de representación sensible no es, pues, el fenómeno, sino algo externo en sentido trascendental:

$[P]$ or cierto que se puede admitir que algo que, en sentido transcendental, podría estar fuera de nosotros, sea la causa de nuestras intuiciones externas; pero ese algo no es el objeto que entendemos con las representaciones de la materia y de las cosas corporales; pues éstas son solamente fenómenos, es decir, meras especies de representación, que se encuentran siempre sólo en nosotros (A 372/373).

[...] lo que llamamos objetos externos no son nada más que meras representaciones de nuestra sensibilidad, cuya forma es el espacio, pero cuyo verdadero correlatum, es decir la cosa en sí misma, no es conocida por medio de ella, ni puede serlo, [cosa] por la cual, empero, tampoco se pregunta nunca en la experiencia” (A 30/B 45). En Prolegómenos a toda metafísica que haya de poder presentarse como ciencia [Prolegomena zu einer jeden künftigen Metaphysik, die als Wissenschaft wird auftreten können], afirma Kant que los fenómenos "no son cosas (sino solo modos de representación)" (Ak. IV, 293). Citamos la versión castellana: Immanuel KANT: Prolegómenos a toda metafísica que haya de poder presentarse como ciencia, traducción de M. Caimi, Madrid: Istmo 1999.

${ }^{4}$ Allí afirma que dicho objeto puede ser considerado "como noumenon, o mejor, como objeto trascendental". Aplazamos por el momento el análisis de la relación entre los conceptos de OT y de noúmeno, dado que este análisis exige una dilucidación previa del sentido que cada uno de estos conceptos asume en el marco de la doctrina crítica. 
A fin de aclarar el estatus propio del objeto externo en sentido trascendental, ha de considerarse la distinción que Kant establece entre lo empíricamente externo y lo trascendentalmente externo:

La expresión: fuera de nosotros lleva consigo una ambigüedad inevitable, ya que tan pronto significa algo que existe como cosa en sí misma diferente de nosotros, tan pronto algo que pertenece meramente al fenómeno externo; por eso, para poner a salvo de la inseguridad este concepto en la última significación, que es en la que propiamente se toma la cuestión psicológica acerca de la realidad de nuestra intuición externa, vamos a distinguir los objetos empíricamente exteriores de aquellos que podrían llamarse así en sentido transcendental, llamándolos directamente cosas que se encuentran en el espacio (A 373).

La expresión "objeto externo" puede remitir, pues, al objeto que se encuentra en el espacio (objeto empíricamente externo), o bien al objeto externo en sentido trascendental, esto es, a "algo que existe como cosa en sí misma”. En aquellos pasajes en los que Kant se refiere al OT como causa o fundamento del fenómeno externo, la expresión OT alude al objeto externo en este último sentido, pues remite a una entidad absolutamente trascendente con respecto al sujeto de la representación ${ }^{5}$.

\footnotetext{
${ }^{5}$ En la expresión OT, el calificativo "trascendental" debe entenderse, pues, como sinónimo de "trascendente" (el término "trascendental” asume diversos significados en los textos kantianos; para un análisis detallado de los mismos, véase: Juan Manuel NAVArro Cordón: "El concepto de 'trascendental' en Kant", Logos. Anales del seminario de Metafísica 5 [1970], pp. 7-26; Ignacio ANGELELLI: "On the origins of Kant's “Transcendental”', Kant-Studien 63 [1972], pp. 117-124). Dado que la expresión “objeto trascendental" alude, pues, a aquello que trasciende absolutamente al entendimiento humano, la noción "objeto" debe ser entendida aquí, no de acuerdo con el sentido técnico que se le asigna en el marco de la doctrina crítica - a saber, como "aquello en cuyo concepto está reunido lo múltiple en una intuición dada” (B 137)—, sino más bien de acuerdo con una acepción más genérica (quizás — podría decirse- como equivalente de entidad). Para un análisis de la significación técnica que asume el término "objeto" en el marco de la doctrina crítica, véase: Paul GUYER: Kant and the Claims of Knowledge, Cambridge: University Press 1987, pp. 117ss.
} 
Tanto el concepto de OT como el de cosa en sí son utilizados, en las obras del período crítico, para aludir a la causa de los fenómenos sensibles, es decir, a aquello que afecta a la sensibilidad dando origen a la intuición empírica ${ }^{6}$. Dado que la entidad afectante es intuida por la sensibilidad bajo las condiciones formales a priori del espacio y el tiempo,

\footnotetext{
${ }^{6} \mathrm{Si}$ se tiene en cuenta la distinción entre el fenómeno y la cosa en sí establecida en el marco de la gnoseología crítica, parecen darse sólo dos posibilidades al momento de determinar el estatus propio de la entidad afectante: o somos afectados por el fenómeno, o bien somos afectados por la cosa en sí. La primera posibilidad ha de ser rechazada: en efecto, no puede decirse que el fenómeno afecte a la sensibilidad, pues en tanto pura representación de la conciencia, no constituye, en rigor, algo propiamente externo a ella (por otra parte, siendo el fenómeno resultado de la afección, no podría ser considerado, a la vez, como su causa). En cuanto a la caracterización de la entidad afectante como cosa en sí, si bien esta posibilidad es rechazada por numerosos intérpretes (ya que parece implicar un uso ilegítimo de las categorías, a saber: la aplicación de la categoría de causa a la cosa en sî), consideramos que ella se ajusta a lo establecido por Kant en diversos pasajes de sus obras críticas (cf. Ak. IV, 289; Ak. IV, 314-315; A 358-359). Si bien el análisis de las dificultades que plantea la cuestión excede los objetivos planteados para el desarrollo de este trabajo, podemos decir que la afección de la sensibilidad por parte de una entidad trascendente al sujeto opera como una suerte de supuesto básico en la doctrina de la sensibilidad desarrollada en la "Estética Trascendental" (cf. ADICKERS: Kant und das Ding..., pp. 4-19; Hans VAiHinger: Commentar zu Kants Kritik der reinen Vernunft, vol. 2, Stuttgart 1892, pp. 472-472; Charles PArsons: "The Transcendental Aesthetic", en Paul Guyer (ed.): The Cambridge Companion to Kant, Cambridge: University Press 1992, p. 66). Para un estudio pormenorizado del problema de la afección en relación con la cosa en sí, véase: Rae LANGTON: Kantian Humility, Oxford: Clarendon Press 2001, pp. 7ss.; Lorne Falkenstein: Kant's Intuitionism. A Commentary on the Transcendental Aesthetic, Toronto: University of Toronto Press 1995, pp. 314-333). Existe aún una tercera posibilidad a fin de establecer el estatus correspondiente a la entidad afectante: se trata de la "doctrina de la doble afección" propuesta por Adickes, doctrina que establece que el objeto empírico afecta al yo empírico, y la cosa en sí, al yo trascendental (cf. Erich ADICKERS: Kants Lehre von der doppelten Affektion unseres Ich, Tübingen: J. C. B Mohr 1929). Sin embargo, los intérpretes posteriores han rechazado la solución propuesta por Adickes, señalando que la misma carece de base textual suficiente (cf. Gerold Prauss: Kant und das Problem der Dinge an sich, Bonn: Bouvier Verlag 1989, p. 194), o que plantea más dificultades de las que permite resolver (cf. Roberto TORRETTI: Manuel Kant. Estudio sobre los fundamentos de la filosofía crítica, Santiago de Chile, Ediciones de la Universidad de Chile: 1967, p. 523). Comentarios críticos acerca de la "doctrina de la doble afección", pueden verse en: KeMP SMITH: A commentary..., pp. 612ss.; CAImI: “La sensación...”, pp. 118-119; François Xavier CHEnET: L'assise de l'ontologie critique: l’ Esthétique transcendantale, Lille: Septentrion1994, pp. 325ss.
} 
este fundamento suprasensible del fenómeno permanece desconocido para nosotros. En cuanto a su carácter suprasensible, éste se deduce de la concepción del tiempo y el espacio como formas a priori de la sensibilidad desarrollada en la "Estética trascendental". En efecto, una vez que ha sido establecido el carácter ideal del espacio y el tiempo (condiciones a priori de la sensibilidad), no cabe atribuir ya las determinaciones espacio-temporales propias de los objetos dados en la experiencia a las cosas tal como son en sí mismas: "como no podemos hacer, de las condiciones particulares de la sensibilidad, condiciones de la posibilidad de las cosas, sino de los fenómenos de ellas, entonces podemos decir que el espacio abarca todas las cosas que pueden presentársenos exteriormente, pero no todas las cosas en sí mismas" (A 27/B 43) ${ }^{7}$.

${ }^{7}$ Diversos intérpretes coinciden en que la tesis crítica que establece el carácter suprasensible de la cosa en sí se deduce a partir de la concepción del espacio y el tiempo como condiciones a priori de la representación sensible (cf. PARSONS: "The Transcendental...", pp. 86-88; Allison: “Kant's concept...”, p. 188; TORRETTI: Manuel Kant..., p. 203; Robert WolfF: Kant's Theory of Mental Activity. A commentary on the Transcendental Analytic of the Critique of pure reason, Gloucester: Peter Smith 1973, p. 313). Cabe señalar que la tesis crítica que afirma el carácter suprasensible de la cosa en sí no contradice el principio kantiano que establece la incognoscibilidad de las cosas en sí, ya que no pretende determinar qué sean las cosas en sí, sino que establece únicamente que las determinaciones propias del objeto como fenómeno no pueden serle atribuidos: "no es propiamente conocimiento, si meramente indico cómo no es la intuición del objeto, sin poder decir qué está contenido en ella; pues entonces no he representado la posibilidad de un objeto para mi concepto puro del entendimiento; porque no he podido dar ninguna intuición que le correspondiese, sino que sólo pude decir que la [intuición] nuestra no es válida para él” (B 149; cf. A 358-359). Por lo demás, el carácter no cognoscitivo de la tesis que establece el carácter suprasensible de la cosa en sí puede ser constatado si se atiende al carácter analítico de dicha tesis; en efecto, la proposición que afirma el carácter inextenso y atemporal de la cosa en sí no es sintética, ya que puede ser deducida a partir del mero análisis del concepto de cosa en sí (noción que designa al objeto tal como ha de ser considerado más allá de las condiciones propias de la intuición sensible). Al tratarse de una proposición analítica, no constituye, pues, un auténtico conocimiento, ya que la mera explicación de lo implicado en un concepto no implica efectivamente, para Kant, conocimiento alguno (cf. A 10/B 14). Para un análisis de esta cuestión, véase: Henry ALLISON: El idealismo trascendental de Kant: una interpretación y defensa, traducción de D. M. Granja Castro, Barcelona: Anthropos 1992, pp. 389ss. Por lo demás, la caracterización kantiana de la cosa en sí como entidad existente (cf. infra, nota 9) plantea importantes dificultades a la interpretación que sostiene que 
En cuanto a la función específica de los conceptos de OT y de cosa en sí en el marco de la doctrina crítica, puede decirse que ambas nociones aluden al límite insuperable del conocimiento humano, por cuanto se refieren a aquello que jamás puede ser dado ante la sensibilidad, permaneciendo así absolutamente desconocido para nosotros. La doctrina crítica establece, efectivamente, que los objetos fenoménicos constituyen el objeto exclusivo del conocimiento humano, conocimiento que en ningún caso alcanza a la cosa en sí: "qué clase de cosa en sí misma (objeto transcendental) sea la materia, nos es, por cierto, desconocido" (A 366) ${ }^{8}$. Más aún, dado que nuestra sensibilidad sólo nos permite intuir los objetos tal como son dados bajo las condiciones formales de la representación sensible, no podríamos jamás comprender la naturaleza de este fundamento suprasensible del fenómeno: "el objeto transcendental que pueda ser el fundamento de este fenómeno que llamamos materia, es un mero algo de lo cual ni siquiera entenderíamos lo que es, aunque alguien pudiera decírnoslo" (A 277/B 333) ${ }^{9}$.

las proposiciones kantianas referidas a la cosa en sí son de carácter analítico, ya que, mientras que el carácter suprasensible de la cosa en sí podría ser deducido a partir del mero análisis del concepto de cosa en sí, es evidente que no ocurre lo mismo en el caso de la categoría de existencia; en efecto, señala Kant — en el marco de su crítica al "argumento ontológico"- que la existencia no es un predicado que pueda estar contenido en el mero concepto de un objeto (cf. A 596/ B 624). Dado que las proposiciones existenciales son, en todo caso, de carácter sintético, sólo pueden basarse en la experiencia (cf. A 715/B 743). Debe concluirse, pues, que no todas las afirmaciones kantianas referidas a la cosa en sí pueden ser consideradas como afirmaciones no cognoscitivas en virtud de su pretendido.

${ }^{8}$ Cf. A 45-56/B 63; A 190-191/B 235-236.

${ }^{9}$ Cabe señalar que afirmar la imposibilidad de conocer el OT (o cosa en sí) no implica que sea cuestionada su existencia. Kant declara, en efecto, que sería absurdo "si no admitiésemos las cosas en sí mismas, o si pretendiésemos presentar nuestra experiencia como el único modo posible de conocimiento de las cosas, y por tanto, presentar nuestra intuición en el espacio y en el tiempo como la única intuición posible, y nuestro entendimiento discursivo como el prototipo de todo entendimiento posible, y si, por consiguiente, pretendiésemos que se tuvieran los principios de la posibilidad de la experiencia por condiciones universales de las cosas en sí mismas" (Ak. IV, 350-351). Diversos pasajes de la $\mathrm{KrV}$ y de Prolegómenos permiten constatar que Kant concibió a la cosa en sí como entidad existente. En el Prólogo a la segunda edición de la $\mathrm{KrV}$, el autor establece que nuestro conocimiento a priori "sólo se dirige a fenómenos, 
De acuerdo con la acepción en que se los ha considerado aquí, los conceptos de OT y cosa en sí resultan perfectamente equiparables, por cuanto remiten ambos al fundamento suprasensible del fenómeno, esto es, a aquello que — presumiblemente — afecta nuestra sensibilidad dando origen a la intuición empírica. Esta correspondencia entre ambos conceptos permite afirmar acerca del OT aquello que puede afirmarse acerca de la cosa en sí. Un breve comentario acerca del sentido específico que este último concepto asume en el marco de la doctrina crítica permitirá, pues, establecer de manera más precisa el sentido que la noción de OT asume en tanto sinónimo de objeto trascendente.

Puede decirse, en primer lugar, que la noción de cosa en sí designa en los textos kantianos al correlato necesario del fenómeno. Si por fenómeno entendemos al objeto tal como es dado ante la sensibilidad (es decir, al objeto tal como es dado bajo las condiciones a priori de la representación sensible), el concepto de cosa en sí alude en cambio al objeto en tanto entidad independiente de nuestra sensibilidad:

Se sigue también, de manera natural, del concepto de un fenómeno en general: que a éste debe corresponderle algo

mientras que deja de lado a la cosa en sí misma [como una cosa que es], por cierto, efectivamente real en sí [für sich wirklich], pero desconocida para nosotros" (B XX). En el \$26 de la Analítica de los conceptos, observa que "los fenómenos son sólo representaciones de cosas que están presentes sin ser conocidas en lo que respecta a lo que puedan ser en sî" [Allein Erscheinungen sind nur Vorstellungen von Dingen, die, nach dem, was sie an sich sein mögen, unerkannt da sind] (B 164). En el $\$ 13$ de Prolegómenos afirma: "admito, ciertamente, que hay cuerpos fuera de nosotros, esto es, cosas que conocemos mediante las representaciones que nos produce su influjo sobre nuestra sensibilidad, aunque nos son completamente desconocidas en lo que respecta a cómo sean en sí mismas; cosas a las que damos el nombre de cuerpo, palabra que entonces significa solamente el fenómeno de aquel objeto desconocido para nosotros, pero no por ello menos real [aber nichs desto weniger wirklichen Gegesntandes]" (Ak. IV, 289). Respecto de la existencia del OT (entendido como cosa en sî), observa Cameron: "Yet, by 'unknowable', it is clear that Kant does not mean that existence of the transcendental object is in doubt! Rather, I cannot know what it is, although I can be assured that it is". Evan Cameron: "God, Kant, and the Transcendental Objekt. An Investigation into Kantian Critique of the Ontological Argument" en Gerhard Funke(ed.): Akten des 4. Internationalen Kant-Kongresses (Mainz, 1974), New York: Walter de Gruyter 1974, II. 5, p. 349. 
que no es, en sí, fenómeno, porque un fenómeno no puede ser nada en sí mismo y fuera de nuestro modo de representación, y por tanto, si no ha de resultar un perpetuo círculo, la palabra fenómeno indica ya una referencia a algo cuya representación inmediata es, ciertamente, sensible, pero que en sí mismo, sin esta constitución de nuestra sensibilidad [...] debe ser algo, es decir, un objeto independiente de la sensibilidad (A 251-252).

Al concepto de fenómeno corresponde necesariamente el concepto de algo real en sí (i. e., de "algo que no es, en sí, fenómeno"), pues —señala Kant—sería absurdo que hubiese fenómeno "sin que hubiese algo que apareciese” (B XXVI- XXVII) ${ }^{10}$. Ahora bien, la correspondencia entre el fenómeno y la cosa en sí no ha de ser entendida en términos ontológicos: efectivamente, Kant no afirma que al fenómeno sensible le corresponde un fundamento suprasensible ontológicamente independiente de aquél, sino que suele caracterizar al fenómeno y a la cosa en sí como nociones que remiten a dos maneras de considerar un objeto único, aquel que es dado en la experiencia. Así señala, en el prólogo a la segunda edición de la $\mathrm{KrV}$, que la doctrina crítica "enseña a tomar el objeto en una doble significación, a saber, como fenómeno o como cosa en sí misma” (B XXVII). El fenómeno y la cosa en sí no constituyen, pues, dos entidades diversas e independientes, sino dos dimensiones bajo las cuales es considerado el objeto dado en la experiencia, en el marco de la reflexión trascendental:

[E]n el fenómeno, los objetos, e incluso las maneras de ser que les atribuimos, son considerados siempre como algo efectivamente dado; sólo que en la medida en que esa

\footnotetext{
${ }^{10}$ Esta correlación necesaria entre los conceptos de fenómeno y de cosa en sí se basa en la etimología del término fenómeno: el vocablo alemán Erscheinung (fenómeno) proviene del verbo erscheinen (aparecer). Si el fenómeno es aparecer, ha de ser necesariamente un aparecer de algo, algo que no constituye, en sí mismo, una entidad fenoménica (este algo que aparece como fenómeno será caracterizado, en el marco de la filosofía crítica, bajo el concepto de cosa en sî).
} 
manera de ser depende solamente de la especie de intuición del sujeto en la relación que con él tiene el objeto dado, ese objeto, como fenómeno, se diferencia de él mismo como objeto en sí (B 69, nuestro subrayado).

[S]i a ciertos objetos, como fenómenos, los llamamos entes sensibles (Phaenomena), distinguiendo la manera como los intuimos, de la constitución de ellos en sí mismos, va implícito ya en nuestro concepto que, por así decir, les contrapongamos a ellos [es decir, a los fenómenos], estos [objetos] mismos, [tomados] según esta última constitución [aquella que les corresponde en tanto objetos en sí] (B 306, nuestro subrayado).

La distinción crítica entre fenómeno y cosa en sí no implica, pues, la adhesión de Kant a un dualismo metafísico (que resultaría incompatible con los principios fundamentales de la doctrina crítica), sino que aparece como distinción de carácter estrictamente epistemológico: al considerar al objeto dado como fenómeno, lo consideramos en relación con las condiciones a priori de la representación sensible; al considerarlo, en cambio, más allá de toda relación con nuestra sensibilidad, lo pensamos como cosa en $s i^{11}$.

Aquello que hemos indicado respecto de la cosa en sí puede ser afirmado acerca del OT. En primer lugar, se trata aquí de un concepto

\footnotetext{
${ }^{11}$ La interpretación epistemológica de la distinción crítica entre fenómeno y cosa en sí —anunciada en los trabajos de H. Heimsoeth, E. Adickes, J. H. Paton, y desarrollada más recientemente en las obras de G. Prauss, G. Bird y H. Allison, entre otrosse opone, pues, a la interpretación ontológica, que la considera en cambio como una distinción referida a dos mundos diversos e irreductibles (el mundo sensible y el inteligible). La interpretación ontológica — que se remonta hasta los propios contemporáneos de Kant y es aún ampliamente aceptada, principalmente en el marco de la literatura angloamericana - suele considerar al idealismo trascendental como una teoría metafísica que establece la incognoscibilidad de lo real, relegando nuestro conocimiento al dominio meramente subjetivo de las representaciones. Actualmente, se alude a esta discusión oponiendo la llamada interpretación de las 'dos perspectivas' a la interpretación de los 'dos mundos' (cf. Karl Ameriks: "Recent Work on Kant's Theoretical Philosophy”, American Philosophical Quarterly 19 (1982), pp. 1-24).
} 
que alude al "objeto independiente de la sensibilidad" (más precisamente: al modo en que consideramos el objeto al hacer abstracción de toda condición propia de la representación sensible). Esta manera de considerar el objeto no es, por cierto, arbitraria, pues aparece como resultado de la concepción crítica del objeto en tanto fenómeno: en efecto, dicha concepción implica reconocer que las características espacio-temporales propias del objeto dado se fundan en las condiciones a priori de la representación sensible y no pertenecen, por consiguiente, al objeto tal como en sí mismo. Hemos señalado que este "objeto independiente de la sensibilidad" es caracterizado por Kant como un fundamento suprasensible del fenómeno y, sin embargo, no constituye un fundamento ontológicamente diverso del fenómeno, sino más bien una dimensión suprasensible del objeto dado (correlato de su dimensión sensible o fenoménica) ${ }^{12}$.

Esta breve reflexión acerca del modo en que ha de ser interpretada la noción crítica de cosa en sí permite establecer en qué sentido ha de entenderse la noción de OT en aquellos pasajes en los que Kant la utiliza como sinónimo de objeto trascendente. No es ésta, sin embargo, la úni-

${ }^{12}$ Podría objetarse que, siendo el OT una dimensión suprasensible del objeto físico, carece de sentido afirmar que aquél afecta nuestra sensibilidad (en efecto, no es fácil comprender en qué sentido una dimensión del objeto físico podría afectarnos, dando así lugar a la otra dimensión de dicho objeto, a saber: su dimensión sensible). Esta dificultad se resuelve fácilmente si tenemos en cuenta que el OT y el fenómeno no constituyen entidades diversas sino dos modos de considerar el objeto dado en la experiencia: al afirmar que aquél nos afecta, no se quiere decir con ello que la dimensión suprasensible del objeto nos afecta, sino más bien que la entidad afectante ha de ser considerada, en el marco de la reflexión trascendental, como entidad no sujeta a determinaciones espacio-temporales (pues tales determinaciones le corresponden únicamente en tanto es representada por la sensibilidad). Respecto de esta cuestión, señala Allison: "Recordemos que la teoría kantiana de la sensibilidad no sólo requiere que algo sea 'dado a' o 'afecte' a la mente; sostiene, además, que este algo llega a ser parte del contenido del conocimiento humano (la 'materia' de la intuición empírica) solamente como resultado de estar sujeto a las formas a priori de la sensibilidad humana (espacio y tiempo). De aquí se sigue, ciertamente, que este algo que afecta a la mente (con lo cual funciona como la causa o fundamento de sus representaciones) no puede ser considerado bajo su descripción empírica (como una entidad espaciotemporal). Hacer esto implicaría asignar a ese objeto, considerado al margen de su relación con la sensibilidad humana, justamente aquellos rasgos que, de acuerdo con la teoría, sólo posee en virtud de esta relación" (AlLison: El idealismo..., p. 383). 
ca acepción en que el concepto de OT es utilizado en el desarrollo de la $K r V$. En la sección siguiente haremos referencia a una segunda acepción que, si bien no resulta equiparable con la primera, se halla no obstante - como tendremos oportunidad de observar — indisolublemente vinculada con ella.

\section{El objeto trascendental como correlato objetivo inma- nente de nuestras representaciones}

La imposibilidad de conocer al OT entendido como objeto trascendente (es decir, como correlato trascendente de nuestras representaciones) plantea dificultades al momento de establecer la validez objetiva del fenómeno. Efectivamente, siendo el fenómeno una representación, ha de ser necesariamente referido a un objeto, pues de otro modo no podría ser garantizada su objetividad (esto es, no podría garantizarse la concordancia de las diversas representaciones fenoménicas, concordancia que sólo es posible por su referencia a un objeto común $\left.{ }^{13}\right)$. Dado que no es posible establecer la referencia del fenómeno a su correlato trascendente (pues éste resulta absolutamente desconocido para nosotros), la conciencia recurre a un objeto inmanente, que - podría decirse- opera como sustituto del objeto trascendente, al momento de establecer la correlación entre la representación y su objeto. La noción de OT, entendida en una nueva acepción, alude precisamente a este objeto inmanente, más precisamente: al concepto de objeto en general. De acuerdo con esta segunda acepción, el término OT no designa ya a un objeto trascendente, sino al mero concepto de un objeto y, por tanto, a un tipo de objetivi-

${ }^{13}$ Acerca del paralelismo que Kant establece entre la representación subjetiva (como estado de conciencia) y el fenómeno (representación externa de valor objetivo), observa Allison: "This explicit parallelism between representations in the first instance (obviously viewed empirically as ideas in the mind) and appearances viewed transcendentally as representations «in us» is further evidence for our contention that the whole problem of, and need for, the concept of transcendental object grew out of the fact that Kant's transcendental philosophy was grounded in a re-interpretation of the theory of ideas. Just as representations in the first sense have an empirical object, so appearances viewed as representations must likewise have their object" (cf. AllisON: "Kant's concept...", p. 182). 
dad inmanente a la conciencia. En este sentido es utilizado el término en una serie de pasajes suprimidos en la segunda edición de la $\mathrm{KrV}$, en los que Kant se refiere a las condiciones que ha de satisfacer una representación para constituirse como representación de carácter objetivo. En la Deducción trascendental de los conceptos puros del entendimiento (primera edición), ${ }^{14}$ el autor realiza una importante observación referida al modo en que ha de ser entendida la relación entre el conocimiento y su objeto en el marco del idealismo trascendental:

¿Qué se entiende, entonces, cuando se habla de un objeto que corresponde al conocimiento, y que por tanto es diferente de él? Es fácil comprender que ese objeto debe ser pensado sólo como algo en general $=\mathrm{X}$, porque fuera de nuestro conocimiento no tenemos nada que pudiéramos poner frente a ese conocimiento como algo que le correspondiese. Pero encontramos que nuestro pensamiento de la referencia de todo conocimiento a su objeto lleva en sí algo de necesidad, pues éste es considerado como aquello que se opone a que nuestros conocimientos sean determinados al azar, o de manera caprichosa, y antes bien [hace] que estén determinados a priori de cierta manera; porque al tener que referirse a un objeto, necesariamente concuerdan entre sí con respecto a éste; es decir, deben tener aquella unidad en la que consiste el concepto de un objeto. Es claro, sin embargo, que, como sólo tratamos con el múltiple de nuestras representaciones, y aquel $\mathrm{X}$ que les corresponde (el objeto), puesto que tiene que ser algo diferente de todas nuestras representaciones, no es nada para nosotros, [entonces] la unidad que el objeto hace necesaria no puede ser

\footnotetext{
${ }^{14}$ No nos detendremos a analizar los argumentos desarrollados en la llamada "Deducción A", dado que la complejidad de esta sección de la $\mathrm{KrV}$ exige un estudio pormenorizado que, por razones de espacio, no podríamos desarrollar aquí. Para un estudio detallado de esta sección, véase: Michael BARKER: “The Proof Structure of Kant's ADeduction”, Kant-Studien 92 (2001), pp. 259-282.
} 
otra cosa que la unidad formal de la conciencia en la síntesis múltiple de las representaciones (A 104-105).

Señalamos ya que los objetos dados en la experiencia son concebidos, en el idealismo crítico, como entidades puramente fenoménicas. Indicamos asimismo que, en virtud de su estatus representacional, los fenómenos exigen ser referidos a un objeto, de manera tal que pueda ser garantizada su validez objetiva. Sin embargo, el objeto trascendente correspondiente al fenómeno nos es absolutamente desconocido (o, como afirma Kant en el pasaje citado, "no es nada para nosotros”), razón por la que no podemos recurrir a éste en tanto correlato objetivo de la representación fenoménica. ¿A qué objeto ha de ser referido, entonces, el fenómeno, puesto que no tenemos relación con objeto alguno más allá del orden de la representación? Dado que el objeto trascendente correspondiente a la representación no puede ser intuido por la sensibilidad (que sólo intuye fenómenos), la unidad que debería proporcionar tal objeto ha de ser proporcionada por la conciencia, ${ }^{15}$ más precisamente, por un concepto de objeto concebido por ella, a saber: el concepto de un objeto en general ${ }^{16}$.

\footnotetext{
${ }^{15}$ En este sentido, sostiene Longenesse que el "objeto = X" no es algo independiente del acto de juzgar o representar: el objeto representado por el término " $\mathrm{X}$ " depende enteramente del acto de juzgar por el cual atribuimos al mismo determinados predicados (cf. Béatrice Longuenesse: Kant and the capacity to judge. Sensibility and Discursivity in the Transcendental Analytic of the Critique of pure Reason, traducción inglesa de Ch. T. Wolfe, Princeton: Princeton Universitty Press 2000, pp. 108-110).

${ }^{16}$ Respecto de esta cuestión, observa Wolff: "If the objects of my sensuous representations are nothing to me, then in what sense can those representations be said to give me knowledge? How can I know of their conformity to an object which is necessarily hidden from me? [...] At this point, there are two alternative lines of reasoning which Kant may follow. He may decide that there is no sense at all to the notion of an object of representations, and hence that we do not have any knowledge, strictly so called [...]. Or, he may decide to reinterpret the phrase, 'object of representations', thereby preserving the characteristics of objectivity and necessity by explaining them in a different way [...]. Kant chose the latter alternative" (WOLFF: Kant's Theory..., p. 138). Acerca de la relación entre las representaciones y el objeto de conocimiento en el marco de la doctrina crítica, señala Allison que la noción de objetividad debe ser re-interpretada en términos inmanentes a la conciencia (ALLISON: “Kant's concept...”, pp. 178-179). Ob-
} 
De acuerdo con esta nueva acepción, el término OT no remite ya al objeto trascendente sino a un objeto inmanente, punto de convergencia ideal de nuestras representaciones ${ }^{17}$. El término 'trascendental' es utilizado aquí, pues, en su acepción más técnica, ya que remite en este caso a aquel conocimiento "que se ocupa, en general, no tanto de objetos, como de nuestra manera de conocer los objetos, en la medida en que ella ha de ser posible a priori" (B 25). Si bien tanto el OT trascendente como el OT inmanente constituyen objetos no empíricos (y han de ser diferenciados, pues, del objeto físico, dado en el tiempo y el espacio), su carácter trascendental no resulta equiparable: mientras que aquél constituye un correlato trascendente del fenómeno sensible, este último constituye una condición trascendental de la objetividad, en tanto aquello que hace posible garantizar la validez objetiva del fenómeno como representación. El estatus trascendental del OT inmanente remite, pues, a su carácter de condición necesaria de toda representación objetiva en general.

La diversa relación que el OT trascendente y el OT inmanente guardan respecto del fenómeno puede ser constatada, por lo demás, si se atiende a la observación kantiana según la cual el OT "es siempre idéntico en todos nuestros conocimientos". En la "Deducción A" Kant observa, en efecto, que los fenómenos:

$[\mathrm{N}]$ o son cosas en sí mismas, sino que son, ellos mismos, sólo representaciones, que a su vez tienen un objeto, el cual, entonces, ya no puede ser intuido por nosotros, $y$ por eso podría llamarse el objeto no empírico, es decir, [el objeto] transcendental $=\mathrm{X}$. El concepto puro de este objeto transcendental (que efectivamente es siempre idéntico $=\mathrm{X}$ en todos nuestros conocimientos) es aquello que en todos nuestros conceptos empíricos puede suministrar, en gene-

servaciones análogas pueden hallarse en: Horst SEIDL: "Bemerkungen zu Ding an sich und transzendentalem Gegenstand in Kants Kritik der reinen Vernunft", Kant-Studien 63 (1972), p. 148.

${ }^{17}$ Cf. Navarro Cordón: “El concepto...”, pp. 11-12. 
ral, referencia a un objeto, es decir, realidad objetiva (A 108109).

Si la noción de OT en tanto objeto trascendente remite a una dimensión suprasensible del fenómeno, cabe suponer que a cada fenómeno le corresponde un OT (en efecto, si cada uno de los objetos dados en el espacio puede ser considerado como fenómeno, o bien, como OT, habría pues tantos OT como fenómenos dados). Ahora bien, el OT en tanto concepto de un objeto en general no constituye un correlato trascendente del fenómeno sino un objeto formal intencionado por la conciencia a fin de garantizar la validez objetiva de sus representaciones fenoménicas; ${ }^{18}$ de allí que dicho OT pueda ser "siempre idéntico en todos nuestros conocimientos", pues se trata aquí, en rigor, de un concepto de objeto que opera como punto de convergencia ideal de todas nuestras representaciones fenoménicas.

En cuanto a la caracterización del OT como una incógnita ("algo en general $=$ X”), ello podría generar cierta confusión entre ambas acepciones del concepto de OT, pues así como nada podemos saber acerca del OT trascendente, nada podemos conocer tampoco acerca del OT inmanente, aunque por razones muy diversas: el OT trascendente (o cosa en sî) resulta absolutamente incognoscible para el entendimiento humano ya que las condiciones necesarias de nuestra facultad de representación imponen al objeto determinadas características formales (operando así como una suerte de mediación entre el sujeto y el objeto de conocimiento); por su parte, el OT inmanente resulta absolutamente desconocido para nosotros por cuanto constituye la condición última de todo cono-

\footnotetext{
${ }^{18}$ Señala Wolff respecto de este punto: "The concept of an object in general $=\mathrm{X}$ is the pure form of objectivity. It is provided by the mind, which imposes it on the given manifold of perceptions, thereby rendering them 'objective', which is to say giving them relation to an object of knowledge" (WOLFF: Kant's Theory..., p. 136). Para un análisis de la función objetivante desempeñada por OT en tanto concepto de objeto en general, véase: Donald GotTERBARn: "Objectivity Without Objects. A Non-Reductionist Interpretation of the Transcendental Object", en Gerhard Funke (ed.): Akten des 4. Internationalen Kant-Kongresses (Mainz, 1974), New York: Walter de Gruyter 1974, II. 3 , pp. 202ss.
} 
cimiento objetivo en general y, en cuanto tal, no admite ser él mismo objetivado $^{19}$.

Hemos aludido a las razones que permiten sostener que la ambigüedad implicada en el uso kantiano del concepto de OT no es resultado de un mero "descuido terminológico", sino que se funda en principios doctrinales del idealismo crítico: dado que el fenómeno —entidad representacional - no puede ser referido a su correlato trascendente (pues dicho correlato resulta absolutamente desconocido para nosotros), la conciencia apela a un concepto de objeto en general a fin de garantizar la validez objetiva de sus representaciones fenoménicas. Ambas acepciones del concepto se hallan así directamente vinculadas. En el tercer capítulo de la "Analítica de los principios", Kant realiza algunas observaciones que resultan relevantes a fin de establecer de manera más precisa la relación entre dichas acepciones:

Todas nuestras representaciones [...] son referidas por el entendimiento a algún objeto; y puesto que los fenómenos no son sino representaciones, el entendimiento los refiere a un algo, objeto de la intuición sensible, pero entonces este algo es solamente el objeto transcendental. Éste significa empero un algo $=\mathrm{X}$ del que no sabemos nada, ni tampoco podemos, en general, (según la actual disposición de nuestro entendimiento), saber nada, sino que sólo puede servir como un correlatum de la unidad de la apercepción para la unidad de lo múltiple en la intuición sensible, [unidad] por medio de la cual el entendimiento lo unifica en el concepto de un objeto (A 250).

\footnotetext{
${ }^{19}$ En este sentido observa Kant que "este objeto transcendental no se puede separar de los datos sensibles, porque entonces no queda nada por lo cual fuera pensado. En sí mismo no es, por consiguiente, objeto alguno de conocimiento, sino sólo la representación de los fenómenos bajo el concepto de un objeto en general, el cual es determinable por lo múltiple de ellos” (A 250-251).
} 
He aquí uno de los pasajes en los que el término OT es utilizado de manera ambigua. En la proposición inicial, Kant parece referirse al OT trascendente, pues señala que nuestras representaciones deben ser referidas a un algo del que nada sabemos ${ }^{20}$. En la observación final, el término parece ser utilizado en cambio en su segunda acepción, pues se indica que el OT sirve como "un correlatum de la unidad de la apercepción para la unidad de lo múltiple en la intuición sensible"21. Se advierte así la estrecha conexión entre las dos acepciones del término OT: puesto que nada sabemos acerca del OT (correlato trascendente de nuestras representaciones), el referente objetivo de dichas representaciones ha de ser trascendentalmente constituido como un polo de unidad objetiva correlativo a la actividad sintética operada por la conciencia; a la unidad subjetiva de la apercepción corresponde, pues, una unidad objetiva ideal proporcionada por el concepto de un objeto en general. En síntesis: como no podemos conocer las cosas tal como son en sí mismas, pensamos un OT como causa suprasensible del fenómeno:

El entendimiento limita la sensibilidad, sin ensanchar con ello su propio campo; y al advertirle a ella que no pretenda referirse a cosas en sí mismas, sino solamente a fenómenos, piensa él para sí, un objeto en sí mismo, pero sólo como objeto trascendental, que es la causa del fenómeno ( $\mathrm{y}$ por tanto, no [es] fenómeno él mismo) (A 288/B 344-345, nuestro subrayado).

\footnotetext{
${ }^{20}$ Kant caracteriza a este algo como un "objeto de la intuición sensible", expresión que en este caso parece aludir al objeto que asumimos como causa o fundamento de dicha intuición, es decir, al objeto trascendente que afecta nuestra sensibilidad dando origen a la intuición sensible. La expresión "objeto de la intuición sensible" no alude aquí, pues, al fenómeno, definido en el parágrafo inicial de la Estética como "objeto indeterminado de una intuición empírica” (cf. A 20/B 34), sino — reiteramos- al objeto trascendente o cosa en sí.

${ }^{21}$ Rábade Romeo observa que al "polo de unidad subjetiva [constituido por la apercepción] debe responder, al menos hipotéticamente, un polo de unidad objetual [...]. Es un centro de referencia hacia el que convergen 'idealmente' los actos de unificación emanados del polo trascendental-subjetivo de unificación [...]. En pocas palabras, la unidad formal de la apercepción necesita, al menos como pensable, un correlato, al que llamamos objeto trascendental" (RÁBAde Romeo: Kant. Problemas..., pp. 100-101).
} 
La segunda acepción del término OT surge, pues, como respuesta a uno de los problemas cruciales que plantea la doctrina crítica, a saber: la imposibilidad de adscribir el fenómeno a su correlato trascendente (correlato que dicha doctrina declara absolutamente desconocido para el entendimiento humano). En relación con este problema fundamental ha de entenderse, pues, el sentido ambiguo que la noción de OT asume en diversos pasajes de la $K r V^{22}$.

\section{Consideraciones acerca de la conexión entre los concep- tos de objeto trascendental, cosa en sí y noúmeno}

Nos hemos referido a las dos acepciones posibles del concepto de OT, indicando los motivos que permiten explicar el uso ambiguo de dicho concepto en el desarrollo de la gnoseología crítica. Antes de concluir, quisiéramos realizar algunas observaciones acerca de la relación que ha de establecerse entre la noción de OT y los conceptos de noúmeno y cosa en sí, con los que resulta frecuentemente identificada ${ }^{23}$.

\footnotetext{
${ }^{22}$ Coincidimos con Allison cuando señala que la ambigüedad implicada en el uso kantiano del concepto de OT, lejos de ser resultado de un descuido terminológico, constituye una consecuencia ineludible de la doctrina del idealismo trascendental: "It is precisely because we can have no intuition of an object corresponding to our representations (the transcendental object as it is für sich), that we have to interpret the relation between representations and their object as a relation between the representations themselves (The transcendental object as it is für uns). It is therefore not, as is generally supposed, the case that Kant simply has two distinct notions of transcendental object: one of a thing in itself underlying appearances, the other of the necessary synthetic unity of these appearances, which he somehow manage to confuse. Rather, his whole concern is to show that since the former are unknowable, the idea of an object corresponding to appearances must be taken in the latter sense" (ALLISON: "Kant's concept...", p. 184).

${ }^{23} \mathrm{La}$ identificación entre los conceptos de OT, noúmeno y cosa en sí puede conducir — según entendemos- a interpretaciones erróneas de la doctrina crítica. A modo de ejemplo, puede aludirse a las observaciones realizadas por Grabau acerca de la cosa en sí, a la que el autor parece identificar con el noúmeno en sentido positivo: "The disadvantage of Kant's doctrine is that he often talks of this functional term [the concept of a thing in itself] as a thing, an object even, which might appear as it really is to some nonsensuous intuition" (Richard GRABAU: "Kant's concept of the Thing-in-itself: an interpretation", The Review of Metaphysics XVI-4 [1963], p. 778). Nuestro análisis precedente permite concluir que la cosa en sí no se reduce, en el marco de la gnoseología
} 
Consideremos, en primer lugar, uno de los pasajes a los que hemos aludido anteriormente, en el que Kant parece utilizar los conceptos de OT y de noúmeno como nociones en cierta medida equiparables:

[A]quel algo que sirve de fundamento de los fenómenos externos, y que afecta a nuestro sentido de tal manera que éste recibe las representaciones de espacio, de materia, de figura, etc., este algo, considerado como noumenon (o mejor, como objeto trascendental) [...] no es extenso, ni impenetrable, ni compuesto, porque todos esos predicados conciernen solamente a la sensibilidad y a la intuición de ella, en la medida en que somos afectados por tales objetos (por lo demás, desconocidos para nosotros). Pero esas expresiones no dan a conocer qué clase de objeto sea, sino solamente que a él, como [objeto] que es considerado en sí mismo, sin referencia a los sentidos externos, estos predicados de los fenómenos externos no pueden serle atribuidos (A 358-359).

Es evidente que Kant se refiere aquí al OT como cosa en sí, pues alude a aquello que afecta nuestros sentidos dando origen a las representaciones sensibles (y admite ser considerado así como fundamento suprasensible del fenómeno); más adelante se refiere, efectivamente, al objeto considerado en sí mismo ("sin referencia a los sentidos externos") y señala que a dicho objeto no podemos atribuirle ninguna de las determinaciones propias del objeto como fenómeno. Observa, sin embargo, que dicho fundamento puede ser considerado como noúmeno

crítica, a un mero concepto funcional, sino que es asumida por Kant como entidad efectivamente existente (cf. supra, nota 9); en todo caso, el concepto de noúmeno en sentido positivo podría ser entendido como un término puramente funcional, ya que parece ser utilizado a fin de destacar el carácter estrictamente sensible (y, por tanto, pasivo o receptivo) de la intuición humana. La identificación entre las nociones de noúmeno en sentido positivo y de cosa en sí podría conducir, pues, a una interpretación errónea del concepto de cosa en sí, que conduciría, a su vez, a una lectura inadecuada del idealismo crítico: en efecto, si se interpretara a la cosa en sí como un mero concepto funcional, podría arribarse a la interpretación del idealismo kantiano como doctrina filosófica que reduce lo real al orden fenoménico. 
“o, mejor, como objeto trascendental” (A 358). A través de esta suerte de corrección, de carácter más bien retórico, el autor parece sugerir que el concepto de OT resulta más apropiado que el de noúmeno para aludir al fundamento desconocido de los fenómenos (i. e., a las cosas en sî). A fin de establecer las razones de esta presunta corrección debemos analizar brevemente el sentido del concepto crítico de noúmeno.

Dicho concepto alude a "cosas posibles que no son objeto de nuestros sentidos, en tanto que son objetos meramente pensados por el entendimiento" (B 306) y su función principal es establecer los límites insuperables de nuestra sensibilidad (que sólo intuye a los objetos como fenómenos). Sobre la base de esta definición general del noúmeno como ente inteligible, Kant establece una distinción entre dos sentidos diversos del término, que puede aludir, o bien a la cosa en tanto no es intuida por la sensibilidad, o bien al objeto de una posible intuición intelectual (problemática para nosotros):

Si entendemos por noúmeno una cosa, en la medida en que no es objeto de nuestro modo de intuición sensible, pues hacemos abstracción de nuestro modo de intuición de ella; entonces esto es un noúmeno en sentido negativo. Pero si entendemos por tal un objeto de una intuición no sensible, entonces suponemos una particular especie de intuición, a saber, la intelectual, que no es, empero, la nuestra, y de la cual no podemos entender ni siquiera la posibilidad; y eso sería el noúmeno en significado positivo (B 307) ${ }^{24}$.

\footnotetext{
${ }^{24}$ Rábade Romeo distingue cuatro sentidos diversos del concepto de noúmeno en la $K r V$ : noúmeno designa, en primer lugar, lo inteligible, es decir, aquello que es objeto del entendimiento puro (en este sentido, el noúmeno se opone al fenómeno en tanto objeto sensible); atendiendo a una segunda acepción, el término alude al objeto de una intuición intelectual (en este sentido, se opone al fenómeno en tanto objeto de una intuición sensible); según una tercera acepción, el concepto alude a aquello que no puede ser dado en la experiencia (en este caso, se opone al fenómeno en tanto objeto de una experiencia posible); por último, el concepto de noúmeno remite al posible objeto del entendimiento divino, y aquí se opone al fenómeno en tanto objeto de una intuición sensible, propiamente humana (cf. RÁBADE RomeO: Kant. Problemas..., pp. 89-90). El autor señala que, a partir de la segunda edición de la $K r V$, estos cuatro sentidos se
} 
Puede decirse que el noúmeno en sentido negativo resulta equiparable a la cosa en sí (y, por extensión, al OT trascendente): en efecto, se trata de conceptos que remiten al objeto considerado independientemente de toda relación con nuestra sensibilidad. En cuanto al noúmeno en sentido positivo, éste no admite ser identificado con la cosa en sí (ni, por tanto, con el OT trascendente), pues ni la noción de cosa en sí ni la de OT trascendente aluden al posible "objeto de una intuición no sensible", sino que se refieren más bien a aquella dimensión del objeto dado en la experiencia que resulta desconocida para nosotros (dado que la sensibilidad humana sólo representa a los objetos bajo las condiciones formales a priori del espacio y el tiempo).

En el pasaje al que aludimos inicialmente, Kant sugiere que la noción de OT resulta más apropiada que la de noúmeno a fin de caracterizar el fundamento suprasensible de los fenómenos externos. Quizás podría alegarse que la razón de esta preferencia descansa en el carácter ambiguo del concepto de noúmeno (concepto que puede asumir diversos significados, según se lo entienda en sentido negativo o positivo); sin embargo, hemos señalado que también la noción de OT resulta ambigua, por cuanto parece aludir, ya al objeto trascendente, ya a un objeto inmanente a la conciencia (de acuerdo con las dos acepciones que han sido aquí analizadas ${ }^{25}$. Si el concepto de OT parece más apropiado que el concepto de noúmeno para referirse al fundamento suprasensible del fenómeno, tal

reducen, básicamente, a dos: el primero, el segundo y el cuarto corresponden a lo que en 1787 Kant denominará "noúmeno en sentido positivo"; el tercero alude, en cambio, al llamado "noúmeno en sentido negativo" (cf. RÁBADE RomeO: Kant. Problemas..., p. 91).

${ }^{25} \mathrm{Si}$ bien Kant no distingue explícitamente ambas acepciones del término, diversos intérpretes coinciden en que el concepto de OT es utilizado según las dos acepciones mencionadas (cf. George SCHRADER: "The thing in itself in Kantian Philosophy", Review of Metaphysics 2 (1948/1949), p. 533; AlLISON: El idealismo..., p. 374; WolfF: Kant's Theory..., pp. 313-314; ADICKEs: Kant und das Ding. ., pp. 99ss.; PATON: Kant's Metaphysic..., pp. 420-425; Rolf GEORGE: “Transcendental Object and Thing in Itself. The Distinction and its Antecedents", en Gerhard Funke (ed.): Akten des 4. Internationalen Kant-Kongresses (Mainz, 1974), New York: Walter de Gruyter 1974, t. II, p. 191; Moltke S. GRAM: "Things in Themselves: The Historical Lessons", Journal of the History of Philosophy XVIII-4 (1980), p. 414; TORRETTI: Manuel Kant..., p. 502; SEIDL: "Bemerkungen zu Ding...", pp. 305-314). No todos los autores coinciden, 
vez ello se deba a los equívocos que podría suscitar la caracterización de dicho fundamento como noúmeno, es decir, como un "ente inteligible": en efecto, si el fundamento suprasensible del fenómeno fuese considerado como un ente inteligible (i.e., como un mero ente de razón), podría arribarse a la conclusión de que dicho fundamento no es real, y ello implicaría entonces que lo real se reduce, en el marco del idealismo crítico, a la mera realidad fenoménica. La identificación entre el fundamento suprasensible del fenómeno (la cosa en sî́) y el noúmeno podría conducir, pues, a una interpretación subjetivista o fenomenalista del idealismo trascendental, interpretación que — según entendemos - no se ajusta a los principios fundamentales de dicha doctrina ${ }^{26}$.

Una vez aclarado el significado específico de los conceptos de cosa en sí, noúmeno y OT en el marco del idealismo crítico, podemos pasar a analizar la relación existente entre dichos conceptos, análisis que —entendemos - resulta indispensable a fin de evitar los errores de interpretación que podrían suscitarse a partir de la simple identificación entre estos conceptos.

Acerca del OT — en el sentido de objeto trascendente - podemos afirmar lo mismo que hemos afirmado acerca de la cosa en sí, a saber: que constituye una entidad suprasensible que asumimos como causa o

sin embargo, respecto de los motivos que permiten explicar esta doble acepción del concepto.

${ }^{26}$ La interpretación subjetivista considera el idealismo trascendental como una teoría metafísica que establece la incognoscibilidad de lo real, relegando nuestro conocimiento al dominio meramente subjetivo de las representaciones. La interpretación fenomenalista — estrechamente vinculada con la anterior- establece que la doctrina kantiana reduce la realidad a una pura apariencia fenoménica. Ambas interpretaciones constituyen así variantes de lo que podría caracterizarse como la interpretación idealista de la doctrina kantiana (entendiendo por tal aquella interpretación que identifica dicha doctrina con el llamado idealismo convencional). En diversos pasajes de su obra Kant procura evitar esta interpretación de su doctrina (cf. B 69ss.; B 275ss.; Ak. IV, 372ss.); sin embargo, dicha interpretación ha sido hegemónica, desde la época del surgimiento y desarrollo de la doctrina crítica hasta nuestros días (cf. AlLISON: El idealismo..., pp. 30ss.). 
fundamento desconocido de los fenómenos externos. Ahora bien, mientras que el OT trascendente resulta perfectamente equiparable con la cosa en sí, el OT inmanente debe ser claramente diferenciado de ella, ${ }^{27}$ pues la cosa en sí constituye una entidad trascendente a la conciencia, y el OT —en tanto concepto de objeto en general- constituye, por el contrario, un objeto puramente inmanente (i.e., un punto de convergencia ideal, al cual la conciencia refiere sus representaciones a fin de garantizar su validez objetiva).

Respecto de la relación entre el OT y el noúmeno en sentido negativo, este último admite ser identificado con el OT trascendente (siendo ambos equiparables a la cosa en sî). Sin embargo, en sentido positivo el noúmeno no ha de ser identificado con el OT en ninguna de sus acepciones posibles: con respecto al OT trascendente (equiparable a la cosa en sí), si bien en ciertos pasajes Kant caracteriza a la cosa en sí como el posible objeto de una intuición intelectual, ${ }^{28}$ lo cierto es que tanto la cosa en sí como el OT trascendente son concebidos por Kant como una entidad existente, ${ }^{29}$ mientras que la existencia del objeto de una (posible, aunque para nosotros problemática) intuición intelectual no podría ser establecida ${ }^{30}$. Más problemática aún resulta la caracteriza-

${ }^{27}$ Cf. Claudia JÁuregui: Sentido interno y subjetividad. Un análisis del problema del auto-conocimiento en la filosofía trascendental de Kant, Buenos Aires: Prometeo Libros 2008, p. 44.

${ }^{28}$ Cf. infra, nota 30 .

${ }^{29}$ Cf. supra, nota 9.

${ }^{30}$ Podría objetarse que tampoco la existencia del OT trascendente (o cosa en sí) puede ser establecida. Sin embargo, podemos asumir legítimamente dicha existencia, si consideramos que la cosa en sí no constituye una entidad diversa del objeto físico, sino una dimensión suprasensible del mismo (dimensión desconocida para nosotros). Si se acepta la interpretación epistemológica de la distinción crítica entre el fenómeno y la cosa en sí (cf. supra, nota 11), puede decirse, pues, que en la existencia del objeto fenoménico está implicada la existencia de la cosa en sí. Más allá de las importantes dificultades que plantea la aplicación de la categoría de existencia (y de cualquier categoría en general) a las cosas en sí mismas, resulta evidente que Kant las consideró como entidades efectivamente existentes. Si bien el análisis de estas dificultades excede el objetivo que nos hemos propuesto para el desarrollo de este trabajo, cabe señalar que la doctrina crítica deja abierto un espacio para el llamado uso trascendental de los conceptos puros del entendimiento, uso que consiste en referir un concepto puro "a las cosas en general y 
ción del OT inmanente como "objeto de una intuición intelectual", ya que en tanto condición última de toda objetividad, el OT no puede ser constituido él mismo como objeto de conocimiento, y no admite, pues, ser considerado como objeto de un tipo de intuición que, en caso de darse, haría posible un conocimiento inmediato de aquello que es intuido ${ }^{31}$. De hecho, Kant declara explícitamente que el OT no ha de ser llamado noúmeno:

El objeto al cual refiero el fenómeno en general es el objeto transcendental [...]. Éste no puede llamarse noumenon; pues no sé lo que él es en sí mismo, y no tengo concepto alguno de él [...]. No puedo pensarlo mediante ninguna categoría; pues ésta vale para la intuición empírica, para llevarla bajo un concepto de objeto en general (A 253).

en sí mismas" (A 238/B 297). Para un análisis detallado de la posición ambigua asumida por Kant con respecto a la posibilidad de un uso trascendental de los conceptos puros del entendimiento, véase: ADICKES: Kant un das Ding..., pp. 42ss.

${ }^{31} \mathrm{La}$ intuición intelectual es caracterizada por Kant como un modo de representación que - en caso de ser efectivamente posible- daría acceso a un conocimiento inmediato de lo intuido. En el $§ 8$ de la "Estética trascendental", se observa, en efecto, que nuestra intuición "se llama sensible porque no es originaria, es decir, [no es] tal que por ella sea dada la existencia misma del objeto de la intuición (y esta [manera de intuición], por lo que podemos entender, sólo puede corresponderle al Ente originario), sino que depende de la existencia del objeto, y por tanto, es posible sólo gracias a que la capacidad representativa del sujeto es afectada por aquél” (B 72). La intuición intelectual es contrapuesta, pues, a la intuición sensible (humana), la cual, al estar necesariamente sujeta a las condiciones a priori de la sensibilidad (espacio y tiempo), es incapaz de proporcionar un conocimiento de la cosa tal como es en sí, y sólo puede representarla, por consiguiente, como fenómeno. En un texto de 1790 - Über eine Entdeckung, nach der alle neue Kritik der reinen Vernunft durch eine ältere entbehrlich gemacht werden soll- Kant observa, en efecto: "Una de dos: o bien la intuición es, según el objeto, enteramente intelectual, esto es, intuimos las cosas como son en sí [...] o bien no es intelectual, y entendemos por tal [intuición] sólo el modo como somos afectados por un objeto que, en sí mismo, nos es enteramente desconocido" (Ak. VIII, 220). Citamos la traducción española: Immanuel KANT: La polémica sobre la Crítica de la razón pura (Respuesta a Eberhard), traducción de M. Caimi, Madrid: Mínimo Tránsito 2002. La intuición intelectual sería propia de una inteligencia creadora (divina) y daría acceso al conocimiento de la cosa tal como es en sí misma (i. e, independientemente de toda condición subjetiva de la representación). 
Consideramos que en este pasaje se alude al OT en el sentido de objeto trascendente y al noúmeno como objeto de un conocimiento intelectual puro: en efecto, Kant intenta destacar aquí que el OT que asumimos como fundamento del fenómeno no ha de ser considerado como un objeto susceptible de ser conocido a partir de puros conceptos. En la "Nota a la anfibología de los conceptos de la reflexión", declara, sin embargo, que es posible llamar noúmeno al OT, siempre que con ello pretendamos únicamente establecer los límites de nuestra sensibilidad:

$\mathrm{Si}$ queremos llamar noumenon a ese objeto [al objeto trascendental], porque la representación de él no es sensible, somos libres de hacerlo. Pero puesto que no podemos aplicarle ninguno de nuestros conceptos del entendimiento, esta representación permanece vacía para nosotros, y no sirve para nada más que para señalar los límites de nuestro conocimiento sensible, y para dejar un espacio restante, que no podemos llenar ni con la experiencia posible, ni mediante el entendimiento puro (A 288-289/B 345).

La posibilidad de caracterizar al OT como un noúmeno descansa, pues, en el carácter no sensible (no empírico) de la representación de OT, carácter que evidentemente comparte con la representación de un noúmeno. Sin embargo, ha de tenerse presente que esta caracterización no supone conocimiento alguno acerca del OT, pues la representación de éste permanece, en todo caso, absolutamente indeterminada, ya que las categorías no alcanzan a determinar objeto alguno sino al ser referidas a una materia intuitiva provista por la sensibilidad ${ }^{32}$. La caracterización del OT como noúmeno sólo será legítima en tanto apunte a destacar los

\footnotetext{
${ }^{32}$ Kant observa en el pasaje citado que las categorías no pueden ser utilizadas para pensar al OT. Es oportuno señalar que el término pensar es utilizado, en este caso, como sinónimo de conocer; en efecto, si bien las categorías sólo proporcionan un $\mathrm{CO}^{-}$ nocimiento objetivo en la medida en que son referidos a una materia intuitiva provista por la sensibilidad, aquéllas pueden ser empleadas, no obstante, para el pensamiento de aquello que no es dado como objeto de una experiencia posible: "Ahora bien, mediante una categoría pura en la cual se hace abstracción de toda condición de la intuición sensible, única posible para nosotros, no se determina, por consiguiente, ningún objeto,
} 
límites propios de nuestra facultad de representación sensible (al señalar que el fundamento trascendente de los fenómenos externos no puede ser jamás intuido por la sensibilidad, ni, por consiguiente, conocido), sino que —al igual que un noúmeno- sólo puede ser pensado.

En síntesis, los conceptos de noúmeno y de OT sólo admiten ser identificados en la medida en que ambos sean interpretados de acuerdo con aquella acepción que permite equipararlos con el concepto de cosa en sí: entendido como sinónimo de objeto trascendente, la noción de OT coincide, pues, con la de noúmeno en sentido negativo, y ambas remiten al objeto considerado más allá de toda relación con nuestra sensibilidad $^{33}$. Si estos conceptos son interpretados, en cambio, según una acepción diferente (es decir, si se considera al OT como objeto inma-

sino solamente se expresa el pensar de un objeto en general, según diferentes modis" (A 247/B 304).

${ }^{33}$ TORRETTI señala que entre las nociones de cosa en sí, noúmeno en sentido negativo y OT "no es fácil, como se ve, encontrar mucho más que un matiz de diferencia [...]. Combinándolas, concluimos que sólo podemos representarnos las cosas en sí como un noúmeno en sentido negativo, y que no disponemos de otro concepto para pensarlo que el de un objeto trascendental, esto es, un objeto cualquiera, completamente indeterminado e incógnito" (TORRETTI: Manuel Kant..., p. 519). Otros autores señalan, sin embargo, que cada uno de estos términos asume un sentido propio y específico. Tal es el caso de RÁBADE ROMEO, quien se refiere al significado propio de cada uno de ellos contraponiéndolos a la noción de fenómeno, noción que asume, a su vez significados diversos, según sea contrapuesta al noúmeno, a la cosa en sí, o al OT: "frente al término noúmeno, fenómeno significa de ordinario lo sensible [...]. Por el contrario, el fenómeno como opuesto a cosa en sí tiene un matiz bastante distinto. Considerada la cosa en sí como la realidad sin conexión con nuestras representaciones, el fenómeno es precisamente, lo que aparece y lo que, por ello mismo, puede ser representado por nosotros en especial conexión con la sensibilidad [...]; si tenemos en cuenta la caracterización anterior del objeto trascendental como polo referencial de unidad en correlación con el polo formal de la apercepción, no creo que sea aventurado afirmar que, frente a él, la significación que reviste el fenómeno es la de la pluralidad dispersa de las representaciones. Entonces el objeto trascendental es ese algo unitario que tenemos que 'pensar' subyaciendo a dicha pluralidad" (RÁBADE RomeO: Kant. Problemas..., pp. 108-110). Para un breve análisis de la relación entre las nociones de cosa en sí, noúmeno y objeto trascendenta, véase: Howard CAYGILL: A Kant Dictionary, Oxford: Blakwell Publishers 1997, pp. 401-402. 
nente, y al noúmeno como objeto de una intuición intelectual), se trata, entonces, de conceptos inasimilables.

A fin de proporcionar al lector una exposición sintética de las conclusiones a las que hemos arribado a partir del análisis precedente, presentamos un breve cuadro comparativo ${ }^{34}$ :

\begin{tabular}{|c|}
\hline $\mathrm{OTt} \neq \mathrm{OTi}$ \\
\hline $\mathrm{OTt}=\mathrm{C}$ \\
\hline $\mathrm{OTt}=\mathrm{N}-$ \\
\hline $\mathrm{OTt} \neq \mathrm{N}+$ \\
\hline $\mathrm{OTi} \neq \mathrm{C}$ \\
\hline $\mathrm{OTi} \neq \mathrm{N}+$ \\
\hline $\mathrm{OTi} \neq \mathrm{N}-$ \\
\hline $\mathrm{N}-\neq \mathrm{N}+$ \\
\hline $\mathrm{N}+\neq \mathrm{C}$ \\
\hline $\mathrm{N}-\mathrm{C}=\mathrm{OTt}$ \\
\hline
\end{tabular}

Quisiéramos concluir nuestro análisis haciendo una breve referencia a la función específica que los conceptos de OT, cosa en sí y noúmeno asumen en el marco de la gnoseología crítica. Con respecto al sentido epistemológico de cada uno de ellos, tanto el concepto de cosa en sí como el de noúmeno en sentido negativo y el de OT en el sentido de objeto trascendente asumen una función claramente limitativa, por cuanto establecen el límite irrebasable de nuestra facultad de representación sensible (en efecto, se trata de conceptos que aluden a aquello que no puede ser intuido por nuestra sensibilidad, que sólo intuye los objetos como fenómenos) ${ }^{35}$. En cuanto al concepto de noúmeno en sentido positivo, también éste alude, en cierto modo, al carácter limitado

\footnotetext{
${ }^{34} \mathrm{El}$ OT trascendente y el OT inmanente son respectivamente designados bajos las abreviaturas OTt y OTi. Al noúmeno en sentido negativo y al noúmeno en sentido positivo nos referimos respectivamente bajo las abreviaturas $\mathrm{N}-$ y $\mathrm{N}+$, y a la cosa en sí, bajo la abreviatura $\mathrm{C}$.

${ }^{35}$ Cabe señalar que tanto la noción de cosa en sí como la de noúmeno en sentido negativo y la de objeto trascendental remiten a lo incondicionado, por oposición al fenómeno en tanto entidad condicionada: si este último se halla necesariamente sujeto a las condiciones formales de nuestra capacidad de representación, aquéllos remiten a un
} 
de nuestra sensibilidad, pues permite contraponer la intuición sensible a un modo de intuición no sensible, a través del cual sería posible acceder a un conocimiento inmediato acerca de objetos suprasensibles ${ }^{36}$. En lo que atañe a la función epistemológica del OT inmanente, indicamos que el concepto de objeto en general permite conferir validez objetiva a las representaciones fenoménicas, constituyendo así una suerte de correlato objetivo inmanente que opera como sustituto del correlato trascendente del fenómeno (correlato absolutamente desconocido para nosotros) ${ }^{37}$.

tipo de entidad que, por definición, excede a toda condición subjetiva. En la "Dialéctica trascendental" se refiere Kant a lo incondicionado como aquello a lo que tiende la razón en tanto facultad diversa del entendimiento (cf. A 302ss./B 359ss). Si bien el análisis de las connotación práctica de las nociones de cosa en sí, noúmeno y objeto trascendental excede el objetivo específico planteado en este trabajo, cabe destacar la importancia decisiva de dicha nociones para el desarrollo de la filosofía moral kantiana. A las consecuencias prácticas de la investigación gnoseológica desarrollada en la primera crítica se refiere Kant en el Prólogo a la segunda edición (cf. B XXVII-XXXII). Para un análisis de esta cuestión, véase: Erich WEIL: Probleme des Kantischen Denkens, Berlín: Duncker und Humblot 2002, cap. I: "Denken und Erkennen, der Glaube und das Ding an sich", pp. 31-62.

${ }^{36}$ Coincidimos con RÁBADE RomeO cuando afirma que, si bien el noúmeno en sentido positivo no desempeña ninguna función positiva en la constitución de la objetividad, las referencias a este concepto en la $\mathrm{KrV}$ tienen el propósito "de poner constantemente ante los ojos del lector un hipotético polo de comparación frente al cual se dilucide la intrínseca limitación de la objetividad del conocer humano" (RÁBADE RomeO: Kant. Problemas..., p. 91). En un pasaje incluido en la "Nota a la anfibología de los conceptos de la reflexión" (en el cual Kant se refiere — curiosamente- a la significación negativa del noúmeno en términos análogos a aquellos en los que ha aludido, en la segunda edición de la $\mathrm{KrV}$, al concepto de noúmeno en sentido positivo), el autor hace referencia a la función que desempeña el concepto de noúmeno en tanto objeto de una intuición no sensible: "si por ellos [objetos meramente inteligibles] entendemos solamente objetos de una intuición no sensible, [...] entonces por cierto que deben ser admitidos noumena, en esta significación meramente negativa; pues entonces no dicen nada más, sino que nuestra especie de intuición no se dirige a todas las cosas, sino meramente a objetos de nuestros sentidos, y que en consecuencia la validez objetiva de ella es limitada, y por tanto queda lugar para cualquier otra especie de intuición, y por tanto también para cosas [que sean] objetos de ella" (A 286/B 342-343).

${ }^{37} \mathrm{La}$ referencia de toda representación al OT no sólo es necesaria (por cuanto hace posible la constitución del objeto como tal), sino que es, además, a priori, constituyendo así una condición trascendental del conocimiento, que establece que las representaciones fenoménicas deben ser referidas a priori a la unidad necesaria de la apercepción, pues 
En cuanto al sentido ontológico de estos conceptos —esto es, al estatus ontológico correspondiente al tipo de entidad que designan-, tanto la noción de cosa en sí como la de OT trascendente aluden a algo que se asume como real; más precisamente: aluden a una dimensión real de los objetos dados en la experiencia (dimensión absolutamente desconocida para nosotros) ${ }^{38}$. También el concepto de noúmeno en sentido negativo alude al "objeto independiente de la sensibilidad" (razón por la que admite ser equiparado con las nociones de OT trascendente y de cosa en sî́. Sin embargo, el noúmeno constituye - de acuerdo con su significación más general- un ente inteligible, i. e., una entidad meramente pensada por el entendimiento, y si bien admite ser identificado con la cosa en sí y con el OT trascendente en virtud de su función epistemológica, debe ser, no obstante, diferenciado de éstos en lo que atañe a su estatus ontológico: en efecto, mientras la realidad del noúmeno se reduce a su ser pensado, la realidad de la cosa en sí y del OT no parece ser cuestionada en los textos kantianos (aún cuando se afirme la imposibilidad de su conocimiento $)^{39}$. En cuanto al OT inmanente, éste constituye una entidad puramente subjetiva (o, como hemos señalado, un objeto inmanente a la conciencia).

sólo de ese modo alcanzan aquéllas su constitución objetiva (cf. JÁUREGUI: Sentido interno..., p. 48).

${ }^{38}$ En el marco de la doctrina crítica la existencia de una dimensión suprasensible de los objetos dados en la experiencia sólo puede admitirse, desde luego, a modo de supuesto, ya que jamás podremos alcanzar una representación determinada de aquello que no es dado como objeto de una intuición sensible: "Si ahora dirigimos la mirada al objeto transcendental de nuestra idea, vemos que no podemos presuponer en sí misma la efectiva realidad de él de acuerdo con los conceptos de realidad, de substancia, de causalidad, etc., porque estos conceptos no tienen la más mínima aplicación a algo que es enteramente diferente del mundo sensible" (A 679/B 707). La existencia de aquello que no es dado en la experiencia no puede ser demostrada, ya que no contamos, en tal caso, con una materia intuitiva sobre la cual puedan ser aplicados los conceptos puros del entendimiento a fin de determinar un objeto de conocimiento.

${ }^{39}$ Cf. RÁbade Romeo: Kant. Problemas..., p. 97. A propósito de esta cuestión, señala Oizerman que la existencia del noúmeno es meramente problemática, a diferencia de la existencia de la cosa en sí, acerca de la cual Kant no parece tener dudas (cf. OIZERMAN: "Kant's Doctrine...", p. 342). 
A partir de lo expuesto, podemos concluir que la ambigüedad implicada en el uso kantiano del concepto de OT no es producto de una falta de exactitud en el uso de los términos filosóficos, sino que se produce como resultado de la complejidad del problema subyacente, vinculado a la imposibilidad de referir nuestras representaciones fenoménicas a su correlato trascendente (absolutamente desconocido para nosotros). Si bien no hemos llevado a cabo un tratamiento exhaustivo de las múltiples dificultades que surgen en torno a la noción crítica de OT —noción cuya interpretación resulta decisiva para la interpretación del idealismo trascendental kantiano-, hemos procurado aclarar los motivos en los que se basa su problemática sinonimia con las nociones de noúmeno y de cosa en sí, indicando hasta qué punto estos términos admiten ser equiparados y en qué medida han de ser, sin embargo, rigurosamente diferenciados.

\section{Bibliografía}

- Adickes, Erich: Kant und das Ding an Sich, Berlin: Panverlag Rolf Heise 1924.

- — Kants Lehre von der doppelten Affektion unseres Ich, Tübingen: J. C. B. Mohr 1929.

- Allison, Henry: "Kant's Concept of the Transcendental Object", Kant-Studien 59 (1968), pp. 165-186.

- —_ El idealismo trascendental de Kant: una interpretación y defensa, traducción de D. M. Granja Castro, Barcelona: Anthropos 1992.

- Ameriks, Karl: "Recent Work on Kant's Theoretical Philosophy", American Philosophical Quarterly 19 (1982), pp. 1-24.

- ANGelelli, Ignacio: “On the origins of Kant's 'Transcendental”, Kant-Studien 63 (1972), pp. 117-124. 
- BARKer, Michael: “The Proof Structure of Kant's A-Deduction”, Kant-Studien 92 (2001), pp. 259-282.

- BIRD, Graham: "Recent Interpretations of Kant's Transcendental Deduction", en Gerhard Funke (ed.): Akten des 4. Internationalen Kant-Kongresses (Mainz, 1974), t. 1, New York: Walter de Gruyter 1974, pp. 1-15.

- Caimi, Mario: "La sensación en la Crítica de la razón pura”, Cuadernos de filosofía 19 (1983), pp. 109-119.

- _ _ "Structure of the transcendental Aesthetic", Studi Kantiani XI (1996), pp. 27-46.

- _- Leçons sur Kant. La déduction transcendantale de 1787, París: Publications de la Sorbonne 2007.

- Cameron, Evan W.: "God, Kant, and the Transcendental Object. An Investigation into Kantian Critique of the Ontological Argument" en Gerhard Funke (ed.): Akten des 4. Internationalen Kant-Kongresses (Mainz, 1974), II. 5, New York: Walter de Gruyter 1974, , pp. 347-355.

- CaYgill, Howard: A Kant Dictionary, Oxford: Blakwell Publishers 1997.

- Chenet, François Xavier: L'assise de l'ontologie critique: l'Esthétique transcendantale, Lille: Septentrion 1994.

- De Vleeschauwer, Herman: La evolución del pensamiento kantiano. Historia de una doctrina, traducción de R. Guerra, México: Universidad Autónoma de México 1962.

- Erdmann, Benno: Kants Kriticismus in der ersten und in der zweiten Auflage der Kritik der reinen Vernunft, Leipzig: Leopold Voss 1878. 
- Falkenstein, Lorne: Kant's Intuitionism. A Commentary on the Transcendental Aesthetic, Toronto: University of Toronto Press 1995.

- George, Rolf: "Transcendental Object and Thing in Itself. The Distinction and its Antecedents", en Gerhard Funke, (ed.): Akten des 4. Internationalen Kant-Kongresses (Mainz, 1974), t. II, New York: Walter de Gruyter 1974, pp. 186-195.

- GotTerbarn, Donald: “Objectivity Without Objects. A NonReductionist Interpretation of the Transcendental Object", en Gerhard Funke (ed.): Akten des 4. Internationalen KantKongresses (Mainz, 1974), II. 3 New York: Walter de Gruyter 1974, , pp. 196-203.

- Grabau, Richard: "Kant's concept of the Thing-in-itself: an interpretation", The Review of Metaphysics XVI/4 (1963), pp. 770779 .

- Gram, Moltke S.: "Things in Themselves: The Historical Lessons", Journal of the History of Philosophy XVIII/4 (1980), pp. 407-431.

- Guyer, Paul: Kant and the Claims of Knowledge, Cambridge: Cambridge University Press 1987.

- JÁuregui, Claudia: Sentido interno y subjetividad. Un análisis del problema del auto-conocimiento en la filosofía trascendental de Kant, Buenos Aires: Prometeo Libros 2008.

- KANT, Immanuel: Kants gesammelte Schriften, Berlin: herasugegeben von der Königlich Preussischen Akademie der Wissenschaften 1903/1911, I-IX.

- - Crítica de la razón pura, traducción de M. Caimi, Buenos Aires: Colihue 2007. 
- — L La polémica sobre la Crítica de la razón pura (Respuesta a Eberhard), traducción de M. Caimi, Madrid: Mínimo Tránsito 2002.

- — Prolegómenos a toda metafísica que haya de poder presentarse como ciencia, traducción de M. Caimi, Madrid: Istmo 1999.

- Kemp Smith, Norman: A commentary to Kant's Critique of Pure Reason, New York: Humanities Press 1962.

- Langton, Rae: Kantian Humility, Oxford: Clarendon Press 2001.

- Longuenesse, Béatrice: Kant and the capacity to judge. Sensibility and Discursivity in the Transcendental Analytic of the Critique of pure Reason, traducción inglesa de Ch. T. Wolfe, Princeton: Princeton Universitty Press 2000.

- Mc Pherson, Rudisill: "Circles in the Air. Pantomimics and the Transcendental Object $=$ X”, Kant-Studien 87 (1996), pp. 132148.

- Navarro Cordón, Juan Manuel: "El concepto de 'trascendental' en Kant”, Logos. Anales del seminario de Metafísica 5 (1970), pp. 7-26.

- Oizerman, Theodor: "Kant's Doctrine of the Things in Themselves and Noumena", Philosophy and Phenomenological Research XLI/3 (1981), pp. 333-350.

- Parsons, Charles: “The Transcendental Aesthetic", en Paul Guyer (ed.), The Cambridge Companion to Kant, Cambridge: Cambridge University Press 1992, pp. 62-100.

- Paton, H. J.: Kant's Metaphysic of Experience. A Commentary on the First Half of the Kritik der reinen Vernunft, Londres: Georg Allen \& Unwin 1970. 
- Prauss, Gerold: Kant und das Problem der Dinge an sich, Bonn: Bouvier Verlag 1989.

- RÁbade Romeo, Sergio: Kant. Problemas gnoseológicos de la Crítica de la razón pura, Madrid: Gredos 1969.

- Rescher, Nicolas: "On the status of Things in Themselves in Kant”, Synthese 27 (1981), pp. 289-299.

- Schrader, George: "The thing in itself in Kantian Philosophy", Review of Metaphysics 2 (1948/1949), pp. 507-536.

- SEIDL, Horst: "Bemerkungen zu Ding an sich und transzendentalem Gegenstand in Kants Kritik der reinen Vernunft", KantStudien 63 (1972), pp. 305-314.

- TORRetTi, Roberto: Manuel Kant. Estudio sobre los fundamentos de la filosofía crítica, Santiago de Chile, Ediciones de la Universidad de Chile: 1967.

- Vaihinger, Hans: Commentar zu Kants Kritik der reinen Vernunft, vol. 2, Stuttgart 1892.

- Weill, Erich: Probleme des Kantischen Denkens, Berlín: Duncker und Humblot 2002.

- Wolff, Robert P.: Kant's Theory of Mental Activity. A commentary on the Transcendental Analytic of the Critique of pure reason, Gloucester: Peter Smith 1973. 
Discusiones 
